\title{
ANNE GILCHRIST TORNADA "PERSONAGEM": NOTAS SOBRE A ESCRITA BIOGRÁFICA
}

\section{ANNE GILCHRIST MADE "CHARACTER": NOTES ON BIOGRAPHICAL WRITING}

\author{
Daniela Schwarcke do Canto* \\ Universidade Federal de Santa Maria
}

\author{
Anselmo Peres Alós ${ }^{* *}$ \\ Universidade Federal de Santa Maria
}

\begin{abstract}
Resumo: Este trabalho pretende investigar como Anne Gilchrist, importante figura histórica que teve um papel extremamente relevante na divulgação da obra poética Leaves of grass, de Walt Whitman, "abandona” o mundo da vida e é tornada personagem no "mundo do texto", a partir do momento em que é transformada em objeto da escrita biográfica em Anne Gilchrist and Walt Whitman (1900), de autoria de Elizabeth Porter Gould, estabelecendo algumas relações intertextuais com Walt Whitman's Mrs. G.: A Biography of Anne Gilchrist (1991), de Marion Walker Alcaro. Para tanto, realizou-se uma revisão sobre as discussões em torno da escrita de autoria feminina em um contexto em que mulheres são simultaneamente sujeitos e objetos da representação da narrativa biográfica.
\end{abstract}

Palavras-chave: Escrita autobiográfica. Autoria feminina. Anne Gilchrist. Elizabeth Porter Gould.

\begin{abstract}
This paper aims to investigate how Anne Gilchrist, an important historical figure who played an extremely relevant role in the dissemination of Walt Whitman's poetic work Leaves of Grass, "abandons" the real world and is made a character in the "world of text", from the moment she becomes the object of biographical writing in Anne Gilchrist and Walt Whitman (1900), authored by Elizabeth Porter Gould, establishing some intertextual relations with Walt Whitman's Mrs. G.: A Biography of Anne Gilchrist (1991), by Marion Walker Alcaro. For that purpose, a review of the discussions surrounding women's authorship writing in a context in which women are both subjects and objects of the representation of biographical narrative is conducted.
\end{abstract}

Keywords: Autobiographical writing. Female authorship. Anne Gilchrist. Elizabeth Porter Gould.

\footnotetext{
* Graduada, Mestre e Doutora em Letras pela Universidade Federal de Santa Maria (UFSM). Atua como tradutora da Secretaria de Assuntos Internacionais da UFSM. ORCID: https://orcid.org/0000-0003-1949-5990. E-mail: <danidocanto@hotmail.com>.

** Graduado e Doutor em Letras pela Universidade Federal do Rio Grande do Sul (UFRGS). Professor do Departamento de Letras Vernáculas e do Programa de Pós-Graduação em Letras da UFSM. Bolsista de Produtividade em Pesquisa do Conselho Nacional de Desenvolvimento Científico e Tecnológico (CNPq). ORCID: https://orcid.org/0000-0003-2062-2096. E-mail: <anselmoperesalos@ gmail.com>.
} 
Há uma estreita linha que separa a ficção da realidade, e essa linha torna-se ainda mais estreita com o advento da literatura moderna. Daniel Defoe, Samuel Richardson e Henry Fielding são considerados os primeiros escritores de romances, forma literária que, segundo Ian Watt, em seu livro A ascensão do romance: estudos sobre Defoe, Richardson e Fielding (publicado pela primeira vez em 1957), se diferencia da prosa de ficção do passado justamente por sua qualidade e pretensão de realidade (ainda que dentro do regime de uma economia da representação). No seu livro, Watt examina as principais características do romance e diz que a mais relevante delas seria o apego à realidade: “[...] em resumo, consideraram o 'realismo' a diferença essencial entre a obra dos romancistas do início do século XVIII e a ficção anterior” (WATT, 1957, p. 10). Levando em consideração essa afirmativa, podemos dizer que a biografia é, também, um romance.

Pensemos na origem da palavra biografia, de origem grega, que é formada por bio, que significa “vida”, e grafia, que significa “escrita”: portanto, escrever uma vida. É essa facilidade de introduzir o ficcional no factual que faz com que o gênero biográfico e a historiografia andem lado a lado, mas impossibilitados de se tornarem um só. O dicionário Michaelis traz os seguintes verbetes para a palavra "biografia”:

1. Relato não ficcional de uma série de eventos que constituem a vida (ou parte da vida) de uma pessoa, em geral notável por seus feitos ou obras; 2. Livro, filme, peça teatral etc. que constitui uma biografia; 3. Relato ou sucessão de eventos da vida de uma pessoa comum; 4. Relato em forma biográfica, no qual é comum a mistura de fantasia e elementos factuais, em que o autor apresenta a vida de alguma coisa (um animal, uma moeda etc.). ${ }^{1}$

Arnaldo Momigliano (1993) defende que, oficialmente, a biografia teve as suas origens ainda no século $\mathrm{V}$ a. C., mas que, devido à escassez de documentos, existe uma possibilidade de terem existido obras biográficas ainda mais antigas. François Dosse (2009, p. 123), em seu livro O desafio biográfico: escrever uma vida, afirma que “[...] durante muito tempo, da antiguidade à época moderna, o gênero biográfico teve por função essencial identificar. Prestou-se ao discurso das virtudes e serviu de modelo moral edificante para educar, transmitir os valores dominantes às gerações futuras”. O mesmo autor ainda afirma que, sendo um discurso moral e de virtudes, a biografia traz consigo uma expectativa de verdade. Para Dosse (2009), a biografia é um gênero híbrido, algo entre a realidade e a ficção, pois o seu autor precisa movimentar-se entre a veracidade dos fatos, a representação exata da vida do biografado e a impossibilidade de reproduzir fielmente o mundo real, lidando com lacunas existentes nos documentos e depoimentos: “[...] gênero híbrido, a biografia situa-se em tensão constante entre a vontade de reproduzir um vivido real passado, segundo as regras da mimesis, e o polo imaginativo do biógrafo, que deve refazer um universo perdido segundo sua intuição e talento criador” (DOSSE, 2009, p. 55).

Tais lacunas são preenchidas, então, pelo biógrafo, na tentativa de tornar a leitura mais prazerosa e agradável, aproximando a biografia de um romance. No entanto, o autor lembra que

\footnotetext{
${ }^{1}$ Dicionário Michaelis Online. Disponível em: https://michaelis.uol.com.br/moderno-portugues/busca/portugues-brasileiro/ biografia/. Acesso em: 16 dez. 2021.
} 
é importante que o biógrafo baseie suas investigações em documentos originais e autênticos, assemelhando-se, dessa forma, a um cientista, mas não deixa de salientar que escrever uma vida por inteiro é uma ilusão:

[...] o biógrafo pode então tirar o melhor dessa documentação íntima, pois se encontra o mais perto possível do autêntico, a ponto de alimentar às vezes a ilusão de poder restituir inteiramente uma vida. À maneira do cientista, o biógrafo tem que cruzar suas fontes de informação, confrontá-las para se aproximar da verdade. (DOSSE, 2009, p. 59).

Apesar do esforço do biógrafo em manter o seu relato o mais fidedigno possível, a biografia sempre será um pouco ficcional, pois é impossível captar todas as facetas da mentalidade, todas as nuances dos sentimentos de alguém. Dosse (2009) ainda lembra que a própria vida é um “entretecido” de lembranças e de esquecimentos, no qual temos de preencher os hiatos existentes.

O recurso à ficção no trabalho biográfico é, com efeito, inevitável na medida em que não se pode restituir a riqueza e a complexidade da vida real. Não apenas o biógrafo deve apelar para a imaginação em face do caráter lacunar de seus documentos e dos lapsos temporais que procura preencher como a própria vida é um entretecido constante de memória e olvido. Procurar trazer tudo à luz é, pois, ao mesmo tempo a ambição que orienta o biógrafo e uma aporia que o condena ao fracasso. (DOSSE, 2009, p. 55).

Antonio Hohlfeldt (2015, p. 45) compara as pesquisas para se escrever uma biografia a um trabalho de arqueologia: “[...] você tem que [sic] escavar os materiais que sobraram. Por mais que haja tais materiais [...], há que dar sentido a eles, porque, em um primeiro momento, o que temos são fatos ou acontecimentos brutos, fragmentados, que se exaurem em si mesmos”. O autor ainda argumenta que a vida de alguém com muitos feitos certamente resultará em uma biografia mais densa, mais cheia, mas não necessariamente mais interessante do que aquela de alguém com poucas façanhas. O trabalho do biógrafo é justamente saber identificar e valorizar o que há de mais interessante na vida do biografado. Segundo Hohlfeldt (2015):

É um modo de percepção muito específico, que pode partir de um ponto de vista específico, definido desde antes da escrita, mas que pode, igualmente constituir-se ao longo da escrita. É o que dará sentido aos fragmentos, relacionando-os e constituindo uma narrativa, propriamente dita. E saber aproximar isso tudo da sensibilidade de um leitor potencial. (HOHLFELDT, 2015, p. 46, grifos do autor).

Até o século XIX, as biografias preocupavam-se em mostrar os feitos heroicos do sujeito biografado, não necessariamente observando detalhes de linearidade cronológica, o que gera uma preocupação por parte dos historiadores com a credibilidade das obras biográficas, ressalva que se justifica pelo fato de que, com uma maior liberdade para citar acontecimentos e datas sem necessariamente comprovar a autenticidade de suas fontes, as biografias passam a ser, em muitos casos, uma mistura de realidade e ficção. Benito Bisso Schmidt (2014) aponta o século XIX como uma reação à supervalorização do espiritual que ocorreu no século XVIII, como o 
momento em que a história buscou separar-se da literatura, apegando-se a uma maior cientificidade, marcando um período em que se acreditava nos "poderes emancipadores" da ciência, sendo possível, através dela, compreender racionalmente a natureza, a sociedade, o homem, e até mesmo o sobrenatural. Caberia aos historiadores “[...] descrever e/ou explicar o passado de maneira racional e objetiva” (SCHMIDT, 2014, p. 192), enquanto aos literatos caberia “[...] reinventar os fatos de acordo com a sua imaginação e subjetividade” (SCHMIDT, 2014, p. 192). O biógrafo seria ele próprio um "híbrido”, fazendo um trançado de fatos verídicos e de ficção para poder contar a vida do outro.

Dosse (2009) afirma que a escrita da biografia vacila entre o respeito ao quadro cronológico e as liberdades do autor, lembrando que, na ânsia de dar maior eficácia ao relato, o biógrafo pode se utilizar de várias vozes narrativas no decorrer do texto. Para Dosse (2009):

O empenho em dar mais eficácia ao relato pode conduzir ao rompimento da linearidade cronológica e à adoção das múltiplas vozes narrativas que participam dos vários registros de temporalidade [...]. Resulta daí um relato misto que procura reencontrar duas coerências de temporalidade diferentes, a da lógica própria à sucessão dos eventos e a que emana da unidade da pessoa resgatada pelo biógrafo. A narração biográfica não é, pois, como salienta Madelénat, homogênea. É, bem ao contrário, uma estrutura inelutavelmente compósita, uma convergência de relatos diversos enredados uns nos outros. Nisso, lembra a escrita da história e do romance. (DOSSE, 2009, p. 67).

O hibridismo da biografia, ao qual se refere Dosse (2009), dá-se pela forma como ela é escrita. Se, por um lado, ela emprega palavras verdadeiras e descreve situações autênticas, por outro lado, ela recorre, inevitavelmente, à intuição e à imaginação do biógrafo. Conforme Dosse (2009):

À diferença do que ocorre no romance, o emprego de palavras verdadeiras, a descrição de longos estados de espírito autênticos permite situar o gênero biográfico na categoria da escrita histórica. Por outro lado, escrevem-se sempre biografias novas das mesmas personagens, o que não apenas se deve à descoberta de documentos inéditos como se explica pelo surgimento de questões novas, de novos paradigmas interpretativos, e também pela intuição e imaginação do biógrafo - ou seja, por sua capacidade inventiva. (DOSSE, 2009, p. 68).

Miguel Ângelo Montagner (2007), analisando as afirmações de Pierre Bourdieu acerca do discurso (auto)biográfico, aponta que não existe uma linearidade lógica nos acontecimentos da vida de uma pessoa. Todos esses acontecimentos, interligados, mas não necessariamente sequenciais, são organizados depois pelo pesquisador, no momento de produzir a narrativa. Ele explica que, para Pierre Bourdieu, é impossível dar sentido e explicar o “todo” do indivíduo. O grupo no qual o indivíduo está inserido é responsável pela formação de parte de suas características, e é justamente essa parte que fica à descoberta e "visível” ao pesquisador. Podemos explicar somente o que é socialmente determinado, podemos identificar o habitus, a "persona social”, o que acaba por formar um todo biográfico que, na verdade, não existe; ou seja, uma [...] ilusão biográfica: [...] como se fora uma lesma, as marcas distintivas ligadas ao nome, ao biológico 
e ao percorrer histórico dos agentes, acabam por deixar traços quase transparentes que, quando unidos a todos os outros traços dos grupos sociais, definem trajetórias comuns, feixes de percursos muito semelhantes, ou afinal, uma trajetória. (MONTAGNER, 2007, p. 253, grifo nosso).

No artigo Biografia literária: duas tradições, Antônio Marcos Pereira (2012) apresenta o que ele chama de duas “tradições” para a escrita de biografias. A primeira, chamada de tradição monumental, é aquela utilizada em biografias que retratam a vida de grandes personalidades, na sua maioria já reconhecidas como fazendo parte do cânone. Elas são caracterizadas por serem extensas e trazerem a vida do biografado em ordem cronológica. Outra característica importante, ainda segundo Pereira (2012), é o compromisso de trazer à luz fatos da vida do biografado que justifiquem a obra produzida por ele, corroborando, assim, a simetria existente entre vida e obra. A segunda tradição, a chamada tradição processual, traz uma forma totalmente inversa de se conceber uma biografia, e é a mais usada nas biografias modernas. Aqui, a preocupação com a cronologia sede espaço à atenção a fatos da vida do biografado que não é, na maioria dos casos, pertencente ao cânone. O biógrafo é visível, não raro contando ao leitor a história do seu contato com o biografado e expressando a sua opinião pessoal a respeito da pessoa e da obra: “[...] a primeira pessoa do biógrafo é patente e saliente, e as zonas lacunares, os espaços de não-saber, têm oportunidade de tematização e exploração, assim como os impasses, equívocos de juízo, e processos decisórios da natureza mais diversa” (PEREIRA, 2012, p. 42).

\section{II}

Filha de uma família de classe média-alta, Elizabeth Porter Gould nasceu em Manchesterby-the Sea, Massachusetts, em oito de junho de 1848, mas ainda menina se mudou para Chelsea. Gould foi uma grande admiradora do poeta Walt Whitman, tendo publicado Gems from Walt Whitman em 1889, que incluía, além de uma seleção dos poemas extraídos de Leaves of Grass (1855), um poema e um ensaio escritos pela própria Gould; além disso, ela foi a segunda pessoa a obter a permissão do poeta para publicar uma seleção dos seus poemas (a primeira foi William Michael Rossetti).

Mesmo sem grande entusiasmo por parte de Whitman, o livro de Gould teve, na sua maioria, críticas positivas. Edward Whitley (2008) sugere que o livro de Gould foi publicado não só com o intuito de sanar as demandas do mercado editorial do final do século XIX, mas também para agradar ao público e trazer novos leitores à obra de Whitman, enquadrando-a nos costumes da época. Whitley (2008) lembra que, apesar de Gould ser conservadora, no que diz respeito às obras de Whitman e na maneira como elas abordavam principalmente a questão da sexualidade (ela era uma cristã orgulhosa de suas raízes puritanas), ela era, também, uma sufragista que lutava pelos direitos das mulheres, principalmente no que tange à educação, participando ativamente em organizações como Woman Suffrage Association e The Massachussets Society for the University Education of Women, entre outras.

Foi muito provavelmente o grande fascínio de Gould por Whitman e a sua afinidade com as ideias de Anne Gilchrist que a levaram a escrever, em 1900, Anne Gilchrist and Walt Whitman, livro no qual ela relata a relação entre a escritora inglesa e o poeta estadunidense. A Anne Gilchrist descrita por Gould é uma mulher inteligente e de personalidade forte, que já conquistou o seu lugar no círculo literário britânico, mas, ao mesmo tempo, a autora tinha uma 
visão romântica e sentimental de Anne, colocando-a como uma heroína em uma história de amor, dando ao leitor a impressão de estar lendo um romance, e não uma biografia. Marion Walker Alcaro (1991) descreve isso como uma “apoteose”, proporcionada pela extrema admiração da biógrafa pela biografada. Segundo o autor:

Carried away by an almost fatuous admiration of Anne, what Elizabeth Porter Gould creates is not a biography of her but an apotheosis. Hers is a sentimental view of Anne. In her book - which in its emotional climate, often seems perilously close to the nineteenth century's "domestic" novels - she makes Anne the implausibly noble and selfless heroine of a story of implausibly idealized love, "one of the greatest, purest affections this age has revealed"2. (ALCARO, 1991, p. 19).

É relevante dizermos que o livro de Gould sobre o relacionamento de Anne Gilchrist e Walt Whitman foi publicado antes que as cartas que eles trocaram durante seis anos fossem reveladas ao público por Thomas Harned em 1918. Talvez, se Gould tivesse tido acesso a elas, sua visão de Anne fosse outra. Alcaro (1991, p. 19) questiona: “[...] one wonders how 'pure' Miss Gould would have considered Anne's love if she could have known that Anne, in her letters, had urgently offered herself to Walt in body - 'I am yet young enough to bear thee children, my darling' - as well as soul"3.

Datada de 1900, Anne Gilchrist and Walt Whitman foi a segunda biografia escrita e publicada sobre Anne. A primeira, publicada em 1887, dois anos após sua morte, foi escrita pelo seu filho Herbert Harlakenden Gilchrist. Essa biografia, intitulada Anne Gilchrist: her life and her writings, é baseada nas cartas deixadas por Anne Gilchrist e trocadas com amigos e parentes, bem como em suas próprias memórias pessoais como filho da biografada. No prefácio de seu livro, Herbert Gilchrist (1887) diz que, graças ao cuidado que parentes e amigos tiveram com as cartas escritas pela mãe, foi possível recuperar 40 anos de informações. Herbert menciona que pediu autorização de Whitman para publicar as cartas trocadas entre a mãe e ele na íntegra, pois, na sua opinião, eram as mais belas que Anne havia escrito, pedido para o qual o poeta o respondeu: "I do not know that I can furnish any good reason, but I feel to keep these utterances exclusively to myself”4 (GILCHRIST, 1887, p. V). E assim foi feito enquanto ele viveu.

Somente muitos anos após a morte de Whitman, em 1918, que um de seus testamenteiros literários, Thomas Biggs Harned, publicou o livro chamado The Letters of Anne Gilchrist and Walt Whitman, contendo, na íntegra, as cartas trocadas por Anne e Whitman. No prefácio, Harned esclarece que, mesmo sabendo que Whitman não havia permitido que Herbert Gilchrist publicasse as cartas, era de se supor que o poeta tivesse guardado as cartas por mais de 20 anos,

\footnotetext{
${ }^{2}$ Do original: "Levada por uma admiração quase pretenciosa de Anne, o que Elizabeth Porter Gould cria não é uma biografia dela, mas uma apoteose. A dela é uma visão sentimental de Anne. Em seu livro - que em seu clima emocional, muitas vezes parece perigosamente próximo aos romances ‘domésticos’ do século XIX - ela faz de Anne a heroína implausivelmente nobre e abnegada de uma história de amor implausivelmente idealizada, ‘uma das maiores e mais puras afeições que esta época revelou’” (ALCARO, 1991, p. 19, tradução nossa).

${ }^{3}$ Do original: “[...] uma pessoa se pergunta quão ‘puro’ Miss Gould teria considerado o amor de Anne se ela soubesse que Anne, em suas cartas, tinha insistentemente se oferecido a Walt em corpo - 'Eu ainda sou jovem o suficiente para te dar filhos, meu querido’ - assim como em alma” (ALCARO, 1991, p. 19, tradução nossa).

${ }^{4}$ Do original: "Eu não sei se posso fornecer uma boa razão, mas sinto que devo manter essas declarações exclusivamente para mim” (GILCHRIST, 1887, p. V, tradução nossa).
} 
recusando-se a destruí-las (como fizera com tantas outras), porque, talvez, existisse a intenção de um dia torná-las públicas, ou simplesmente porque eram importantes demais para ele. Cartas tão cercadas de carinho e cuidados não poderiam ser simplesmente esquecidas pelo tempo. Harned resolveu, então, dividir com o público o que ele considerava "[...] so beautiful, a tribute to the poetry that he had written, no less than to the personality of the poet"5 (HARNED, 1918, p. 8-9).

Gould projeta, na biografia de 1900, uma Anne de acordo com os padrões sociais da época. Uma Anne corajosa e inteligente, mas, ao mesmo tempo, ainda devotada à família e ao lar. Ela certamente entregou aos leitores o que eles queriam ler, assim como fez com os poemas de Whitman, alguns anos antes. É importante salientarmos que nos referimos, aqui, a uma escritora do século XIX, escrevendo sobre uma outra escritora também do mesmo período. Mesmo as mulheres estando presentes na literatura há muitos séculos, nos mais variados estilos, o período ainda era de hegemonia masculina nas artes como um todo, e elas ainda tinham de lidar com o estigma da inferioridade e o sufocamento de suas ideias pelas imposições sociais e culturais, tal como salienta Rita Terezinha Schmidt:

A atividade criativa da mulher era tida como resultado de seu deslocamento em relação às expectativas culturais de gênero, como por exemplo a sublimação do instinto e função maternal. O próprio ato de escrever, partindo de uma mulher, era considerado como um sinal de mente perturbada, um capricho que deveria ser convenientemente erradicado. (SCHMIDT, 2017, p. 59).

Schmidt (2017, p. 59-60) lembra que, a partir do século XVIII, a mulher de classe média começou a escrever, embora ainda “[...] sujeita à coerção da ideologia da domesticidade e do 'anjo do lar'”, o que demonstrava a marginalidade na qual se encontravam as escritoras da época. Esperava-se delas um texto "sentimental”, o que passava uma imagem “[...] piegas da mulher tola e excessivamente emotiva que celebra a bem-aventurança de seu cativeiro doméstico" (SCHMIDT, 2017, p. 60). No século XIX, as mulheres escreviam basicamente romances, e o que produziam era uma ficção voltada apenas para um público feminino, na qual as temáticas como a vida doméstica e a criação dos filhos eram recorrentes (traços bem presentes na biografia assinada por Gould). Schmidt (2017, p. 62) afirma que mesmo as autoras consideradas "rebeldes” na época, como Jane Austin e George Eliot, são comedidas nas suas colocações, e apesar de apresentarem personagens femininas fortes e "pensantes", revelam uma resignação frente à situação da mulher na sociedade. Vale lembrarmos, aqui, que George Eliot era o pseudônimo de Mary Anne Evans (1819-1880), a qual assinava com um nome masculino com o intuito de preservar a sua vida íntima, mas também para que pudesse publicar obras mais profundas, fugindo do estereótipo de que as escritoras da época somente deveriam publicar romances leves, destinados a outras mulheres.

As escritas feministas, a partir do final do século XIX, têm buscado experimentar alternativas, desenvolvendo uma nova linguagem que vai além daquela engessada pelas convenções patriarcais. Uma linguagem voltada às mulheres e que possa precisar seus pensamentos e suas ideias. É importante salientarmos que a base da escrita feminista é justamente a desconstrução da objetificação do corpo feminino. É possível afirmarmos que a obra de Whitman teve um impacto semelhante em Anne Gilchrist. Quando ela leu Leaves of Grass pela primeira vez, em

${ }^{5}$ Do original: “[...] tão lindo tributo à sua poesia, assim como à personalidade de poeta” (HARNED, 1918, p. 8-9, tradução nossa). 
1869, ela sentiu como se uma energia atravessasse seu corpo, sendo obrigada, muitas vezes, a interromper a leitura para se reestabelecer emocional e fisicamente (GILCHRIST, 1887 apud HARNED, 1918, p. 25). Os poemas de Whitman a fizeram enxergar o seu corpo de uma forma nova, e possivelmente a fizeram consciente de que sua sexualidade havia sido reprimida até então, levando-a a um conflitante sentimento de amor pelo poeta/homem. Na série de poemas Children of Adam, Whitman celebra o corpo humano e sua sexualidade, tópico, aliás, muito explorado pelo poeta, e que lhe rendeu severas críticas durante a sua vida. Não é difícil de imaginarmos o impacto que as palavras do poeta, ditas de forma tão clara sobre um assunto tão delicado - para uma mulher criada por uma mãe vitoriana no século XIX -, tiveram na vida de Anne Gilchrist. Finalmente podendo expressar seus sentimentos, ela escreve a William Rossetti na carta que seria depois publicada como An Englishwoman's Estimate of Walt Whitman:

For the sake of all that is highest, a truthful recognition of this life, and especially of that of it which underlies the fundamental ties of humanity - the love of husband and wife, fatherhood, motherhood - is needed. Religion needs it, now at last alive to the fact that the basis of all true worship is comprised in "the great lesson of reception, neither preference nor denial", interpreting, loving, rejoicing in all that is created, fearing and despising nothing ${ }^{6}$. (HARNED, 1918, p. 37).

Alcaro (1991, p. 27) descreve a biografia de Gould (1900) dedicada a Anne Gilchrist como "carefully and lovingly researched"7, apesar de ser, basicamente, um recorte da biografia escrita por Herbert Gilchrist (1887). Nas suas pesquisas, buscando conhecer um pouco mais da mulher que se tornou tão importante na vida de Whitman, Gould escreveu cartas às pessoas conhecidas de Anne, como Joaquin Miller e William Rossetti, e também recorreu a outras poucas fontes, mas, segundo Alcaro (1991), sua principal fonte de informação e inspiração foi a biografia de Herbert Gilchrist.

A mulher que conta a história de outra mulher. A autora, poeta, e crítica literária que conta a história de outra com tantos dons quanto os seus. Gould narra uma parte da história de Anne Gilchrist com uma admiração que transparece nas suas palavras. Tendo em vista que cada vez que uma história é narrada ela é narrada de uma forma diferente, porque o narrador traz um pouco de si para aquilo que narra, temos a certeza de que a visão que Gould tinha de Anne Gilchrist, a forma como ela entendeu as cartas escritas e as frases ditas, indubitavelmente influenciaram na sua forma de narrar. Notamos na Anne projetada pela obra de Gould uma figura romantizada, a perfeita dona de casa e mãe do século XIX. Susana Kampff Lages, em seu livro Walter Benjamin: tradução e melancolia, afirma que a arte da narrativa é alimentada por influências psíquicas, relacionadas à melancolia. Segundo a autora:

Assim como é praticada pelo narrador tradicional, que conta as suas histórias de cor, a arte da narrativa nutre-se de influxos psíquicos afins à melancolia,

\footnotetext{
${ }^{6}$ Do original: "Para o bem de tudo o que é mais elevado, é necessário um verdadeiro reconhecimento desta vida, e especialmente daquela que está subjacente aos laços fundamentais da humanidade - o amor do marido e da mulher, a paternidade, a maternidade -. A religião precisa dela, agora finalmente viva para o fato de que a base de todo a verdadeira adoração está na 'grande lição da recepção, nem preferência nem negação', interpretando, amando, alegrando-se em tudo o que é criado, não temendo e desprezando nada” (HARNED, 1918, p. 37, tradução nossa).

${ }^{7}$ Do original: “cuidadosamente e carinhosamente pesquisada” (ALCARO, 1991, p. 27, tradução nossa).
} 
pois, como observa Benjamin, para bem memorizar as histórias é preciso um particular estado de distensão, propício à conservação das histórias com o intuito de recontá-las. (LAGES, 2002, p. 127).

Narrar uma vida que foi vivida, de uma pessoa real, é uma tarefa complicada. Dosse (2009, p. 11) diz que “[...] a biografia, como a história, escreve-se primeiro no presente, numa relação de implicação ainda mais forte quando há empatia por parte de autor”. É notável a empatia existente entre a autora, Elizabeth Porter Gould, e sua biografada, Anne Gilchrist. No decorrer de todo o livro, não há uma menção negativa a Anne. Gould traz uma Anne inteligente e educada, que teve em Alexander seu primeiro e verdadeiro amor. Comparada ao que encontramos na biografia posterior, de Alcaro (1991), a perspectiva da narradora/biógrafa Gould é bem mais inocente. Nessa história narrada em terceira pessoa, a biografada é colocada como objeto do olhar da outra. Alguém que parece a conhecer com intimidade, capaz de saber como ela se sentiu ao ler pela primeira vez os poemas de Walt Whitman, como podemos observar na passagem que segue: "[...] she became conscious of a new and most powerful influence affecting her" (GOULD, 1900, p. 3, grifo nosso). A narradora/biógrafa certamente deduziu esse sentimento de Anne tendo acesso às cartas trocadas entre ela e Rossetti, que foram publicadas na biografia de Herbert Gilchrist e que foram sua principal fonte de informação. A biografia é toda entrecortada por trechos de cartas ou de conversas (não podemos saber ao certo, pois a autora não cita as fontes), que aparecem no texto entre aspas.

Gould segue na sua exaltação a Anne Gilchrist, descrevendo os meses anteriores ao casamento com Alexander e os meses que se precederam de uma forma que nem Alcaro (e nem mesmo o filho Herbert Gilchrist) descreve nas suas respectivas biografias de Anne. Gould (1900) toma trechos da carta que Anne escreveu à amiga Julia, já anteriormente citada, e completa dizendo que, aos 20 anos, "[...] came into her life the absorbing love of Alexander Gilchrist"9 (GOULD, 1900, p. 8), e, continuando, diz que “[...] sweet pictures are given us of the happy days after the marriage"10 (GOULD, 1900, p. 8). Entretanto, hoje supomos que o amor não foi tão envolvente assim, e não sabemos se as tais fotos existiram, pois não são reproduzidas no livro, tampouco citadas pelos outros biógrafos.

Aqui, podemos dizer que a perspectiva de Gould com relação a Anne é diferente da que tinha o filho Herbert, que, aliás, fala muito pouco do casamento de Anne e Alexander na biografia que escreveu, limitando-se a dizer que "Anne Burrows and Alexander Gilchrist were married quietly at Colne Church - on Tuesday morning, February 4" ${ }^{\text {th }}$ 1851" 11 (GILCHRIST, 1887, p. 31). Já Alcaro (1991) fala mais do que teriam sido os dias seguintes ao casamento para Anne, levando em consideração sua falta de informação relativa a tudo que envolvia “estar casada”. Gould (1900) segue descrevendo o quanto os dias eram felizes para Anne e o marido, inclusive usando aspas nas suas frases, como se estivesse citando alguém, mas sem mencionar a fonte:

\footnotetext{
${ }^{8}$ Do original: “[...] ela tomou consciência de uma nova e poderosa influência que a influenciava” (GOULD, 1900, p. 3, grifo nosso, tradução nossa).

${ }^{9}$ Do original: “[...] entrou na sua vida o envolvente amor de Alexander Gilchrist” (GOULD, 1900, p. 8, tradução nossa).

${ }^{10}$ Do original: “[...] doces retratos nos são dados dos dias felizes após o casamento” (GOULD, 1900, p. 8, tradução nossa).

${ }^{11}$ Do original: "Anne Burrows e Alexander Gilchrist casaram-se discretamente na Colne Church - na terça-feira pela manhã, do dia 4 de fevereiro de 1851” (GILCHRIST, 1887, p. 31, tradução nossa).
} 
[...] also at Lyme Regis ${ }^{12}$, within sight and sound of the sea, when "daily writing and reading, daily music and daily walks" were theirs - crowned by happy evenings, when he read aloud earnest books, while she worked with the needle, or "read" music, playing and singing all that he selected for her ${ }^{13}$. (GOULD, 1900, p. 8).

Para Ansgar Nünning (2001), a perspectiva da personagem e a perspectiva do narrador são condicionadas pelo conhecimento, pelas características mentais, pelas atitudes e pelo sistema de valores. O conhecimento sobre algo é sempre parcial e limitado pela perspectiva individual da qual é considerado, ou seja, o meu conhecimento sobre algo é limitado ao meu ponto de vista. Podemos dizer que a perspectiva que Gould tem em relação à personagem Anne é limitada ao seu conhecimento, que era oriundo da biografia de Herbert, dos artigos que Anne havia publicado, e dos relatos de amigos e parentes com quem ela manteve contato. A Anne que Gould (1900) narra é fruto do casamento desse pouco conhecimento com sua imaginação, trazendo-nos, como resultado, uma personagem que provavelmente não corresponde, exatamente, à realidade, mas que traz uma versão compatível com os parâmetros de expectativa que circundavam toda e qualquer figura feminina do século XIX.

É preciso lembrarmos que Anne Gilchrist viveu entre 1828 e 1885, e Elizabeth Porter Gould publicou a biografia de Anne em 1900, ainda uma época em que as mulheres tinham pouquíssimos direitos. É compreensível, portanto, que a visão de mundo e a interpretação dos fatos de Gould sejam diferentes da interpretação de Alcaro, que publicou sua biografia 91 anos mais tarde. No texto Arquivos de mulheres e mulheres anarquivadas: histórias de uma história mal contada, Constância Lima Duarte (2018) cita Virginia Woolf, que, em 1929, constatou o número quase insignificante de obras escritas por mulheres, atribuindo isso à misoginia que afirmava a inferioridade intelectual e física das mulheres. Até as últimas décadas do século XIX (e mesmo nas primeiras do século XX), era raro uma mulher que pudesse se expressar livremente e que efetivamente conseguisse concluir um curso superior. Duarte (2018) escreve que, para poderem publicar os seus trabalhos, muitas mulheres usavam pseudônimos, ou publicavam no anonimato, caso da resenha An Englishwoman's Estimate of Walt Whitman, publicada em 1869 por Anne Gilchrist, e que seria a resenha mais cara à reputação do poeta estadunidense no momento em que ele passava por uma fase ruim em sua carreira. William Michael Rossetti, que havia apresentado os poemas de Whitman a Anne, pediu para que ela publicasse a sua resenha anonimamente, temendo que os poemas pudessem soar um tanto inapropriados para uma senhora viúva e mãe de quatro filhos. Isso, sem dúvida, foi uma enorme ambiguidade não percebida por Rossetti na época, pois foi justamente o fato de Anne ser uma "senhora viúva e mãe de quatro filhos” que deu maior credibilidade à resenha.

Obviamente, ao lermos a biografia de Herbert Gilchrist (1887) ou de Gould (1900) hoje, a nossa perspectiva como leitores será bem diferente daquela de um leitor do início do século XX. Citando Ryan (1991), Nünning (2001, p. 211) lembra que construímos o mundo do universo textual de acordo com nossa representação do mundo real: "[...] we will project upon these

\footnotetext{
${ }^{12}$ Lyme Regis é uma cidade costeira da Inglaterra.

${ }^{13}$ Do original: “[...] também em Lyme Regis, vendo e ouvindo o mar, quando 'escritas e leituras diárias, música diária e caminhadas diárias’ eram deles - coroadas por noites felizes, quando ele lia alto livros importantes, enquanto ela trabalhava com a agulha, ou ‘lia’ música, tocando e cantando tudo o que ele selecionava para ela” (GOULD, 1900, p. 8, tradução nossa).
} 
worlds everything we know about reality, and we will make only the adjustments dictated by the text”' ${ }^{\prime 4}$. A perspectiva depende, em última instância, do leitor. Nünning (2001, p. 211) diz que há um "[...] sistema comunicativo de pré-condições, e elas incluem o conhecimento da pessoa, as suas habilidades, suas motivações, suas necessidades, suas intenções, suas expectativas, seu estado mental e físico, bem como as condições econômicas, sociais, políticas e culturais sob as quais essa pessoa vive”. A perspectiva do narrador é semelhante à da personagem, porém, enquanto a imagem da personagem é construída pela fala do narrador e as suas próprias ações no texto, a do narrador é construída apenas pelas suas palavras. Todavia, alerta o autor, em ambos os casos, as informações fornecidas pelo texto são complementadas por inferências por parte do leitor.

A morte do marido foi tratada de forma bastante superficial, citando em poucas linhas a doença e a morte de Alexander e dizendo que ela precisou mudar-se com os filhos para outra casa porque não poderia ficar onde "[...] life had been so full of blessing”15 (GOULD, 1900, p. 11). Alcaro (1991, p. 94) explica que, no século XIX, viúvas eram vistas como “[...] a helpless and pitiful creature" ${ }^{\text {" }}$. Não querendo voltar para a casa da mãe, como seria de costume após a morte do marido, e também sabendo que "[...] remaining at 6 Cheyne Row, with its bitter memories, would be unbearably painful”"17 (ALCARO, 1991, p. 94), Anne resolveu encontrar um novo local para recomeçar.

Durante todo o texto de Gould (1900), é possível notarmos as impressões da biógrafa/ narradora. O uso de expressões como "she felt" (ela sentiu), "she never forgot" (ela nunca esqueceu) e "she believed" (ela acreditava) denotam claramente o quanto a narradora se envolve com a personagem, o quanto ela acredita que podia "entrar” na cabeça de Anne e absorver-lhe os pensamentos. A narradora mantém-se, em quase todo o texto, de uma forma que o leitor acredita que ela faz parte da história. Ela dá opiniões e coloca os pensamentos de Anne como certos, verdadeiros. Esse tipo de narrador, chamado de ouvert por Seymour Chatman (citado por Nünning), coloca-se de forma semelhante às outras personagens da história: “[...] the reader treats their beliefs, projections, wishes and opinions as existing on a par with those of characters"18 (NÜNNING, 2001, p. 214). No trecho que segue, podemos ver claramente ao que Nünning se refere (a biógrafa/narradora “coloca-se” na história no momento em que ela descreve a reação de Anne ao ler um dos poemas de Whitman):

Even for the prostitute she found him divinely tender and sympathetic, as in The City Dead House. I doubt if that poem will ever be more appreciated by any human being than by this woman who could write that inspired letter to Dante Gabriel Rossetti, on "Jenny", when his first volume of poems appeared in 1870 - a poem which moved her to anguish, coming upon her "after she

\footnotetext{
${ }^{14}$ Do original: “[...] projetamos nesses mundos tudo o que sabemos da realidade, fazendo apenas os ajustes ditados pelo texto" (NÜNNING, 2001, p. 211, tradução nossa).

${ }^{15}$ Do original: “[...] a vida fora tão cheia de bençãos” (GOULD, 1900, p. 11, tradução nossa).

${ }^{16}$ Do original: “[...] uma criatura impotente e lamentável” (ALCARO, 1991, p. 94, tradução nossa).

${ }^{17}$ Do original: “[...] ficar na Cheyne Row número 6, com suas lembranças amargas, seria insustentavelmente doloroso” (ALCARO, 1991, p. 94, tradução nossa).

${ }^{18}$ Do original: “[...] o leitor trata as suas crenças, suas projeções, seus desejos e suas opiniões como existentes no mesmo nível daqueles da personagem” (NÜNNING, 2001, p. 214, tradução nossa).
} 
had been gazing into the very sanctuary of love where women sat divinely enthroned"19. (GOULD, 1900, p. 20, grifo nosso).

Vale lembrarmos que o primeiro contato de Anne com os poemas de Whitman foi através de uma seleção feita por Rossetti. Nessa seleção, Rossetti havia “cortado” algumas partes, até mesmo alguns poemas inteiros, por achar que eles não seriam "bem-vistos” pelo público inglês. Palavras como "womb" (ventre) e "prostitute" (prostituta) foram subtraídas na versão de Rossetti, como coloca Paul Ferlazzo (s.d., apud ALCARO, 1991, p. 119): “[...] a properly dressed up Whitman invited to a proper afternoon tea" ${ }^{20}$. Alcaro (1991) lembra que foi ao ler a versão completa dos poemas que Anne experimentou algo totalmente novo para ela. Foi ali que ela encontrou o verdadeiro Walt Whitman, o poeta que cantava as alegrias, a "satisfação do sexo" (ALCARO, 1991, p. 119).

Ao tomar conhecimento das palavras do poeta estadunidense, Anne Gilchrist deu-se conta, pela primeira vez, das suas frustrações sexuais, dos desejos reprimidos, da total falta de liberdade que limitava as mulheres do seu tempo; da vergonha do corpo, dos sentimentos "impuros” que as moças precisavam dominar. Através das palavras de Whitman, Anne entendeu o que faltou na sua vida, no seu casamento com Alexander. Alcaro (1991) descreve esse momento da seguinte forma:

In Whitman's insistence that sex should be a glorious experience for both male and female, Anne had found confirmation at last of the instincts of her own healthy body and confirmation of the belief she had always held that something vital had been missing in her marriage to Alex [...] Anne felt, perhaps for the first time without guilt, the impulse to reach out her hand and touch in turn. The measure of her sexual frustration during all her adult life - the torment of instincts denied and dreams that compounded bewilderment - can be seen in her response to the whole of Walt's poetry. This time Anne Gilchrist responded to the Poet of the Body totally, honestly, logically - with her own body. And with a passionate love that she had never known before ${ }^{21}$. (ALCARO, 1991, p. 119-120).

Ao comparar as palavras de Alcaro (1991) com as de Gould (1900) para descrever o mesmo momento, temos uma clara visão de como as mulheres tinham dificuldades em expressar seus sentimentos em relação ao sexo e às coisas consideradas “mundanas”. Gould (1900) escreve:

\footnotetext{
${ }^{19}$ Do original: “Até para a prostituta ela o achou divinamente sensível e simpático, como em The City Dead House. Eu duvido que esse poema seja algum dia mais apreciado por qualquer ser humano do que por essa mulher que pôde escrever aquela inspirada carta a Dante Gabriel Rossetti a respeito de ‘Jenny’, quando seu primeiro volume de poemas apareceu em 1870 - um poema que a levou à angústia, a atingindo ‘depois de ela estar olhando para o santuário de amor onde a mulher sentava divinamente glorificada’” (GOULD, 1900, p. 20, grifo nosso, tradução nossa).

${ }^{20}$ Do original: “[...] um Whitman adequadamente vestido para um adequado chá da tarde” (ALCARO, 1991, p. 119, tradução nossa).

${ }^{21}$ Do original: "Na insistência de Whitman que sexo deveria ser uma experiência gloriosa tanto para o homem quanto para a mulher, Anne finalmente encontrou a constatação dos instintos de seu corpo sadio, e a confirmação de sua convicção de que algo vital tivesse faltado no seu casamento com Alex [...] Anne sentiu, talvez pela primeira vez sem culpa, o impulso de estender a mão e tocar de volta. A medida de sua frustração sexual durante toda a sua vida adulta - o tormento dos instintos negados e dos sonhos que agravavam a desorientação - podem ser vistos na sua resposta à poesia completa de Walt. Dessa vez Anne Gilchrist respondeu ao Poeta do Corpo totalmente, honestamente, logicamente - com seu próprio corpo. E com um amor passional que ela jamais havia conhecido” (ALCARO, 1991, p. 119-120, tradução nossa).
} 
She used to think it was great "to disregard happiness, to press on to a high goal careless, disdainful of it". Now she fully saw there was nothing so great as "to be capable of happiness"; to pluck it out "each moment and whatever happens"; to find that one can ride "as gay and buoyant on the angry, menacing, tumultuous waves of life, as on those that glide and glitter under a clear sky"; that it is not "defeat and wretchedness which come out of the storm of Adversity, but strength and calmness"22. (GOULD, 1900, p. 18).

Ela continua descrevendo as reações de Anne: “[...] as never before, she realized the glory of being a woman, of being a mother" 23 (GOULD, 1900, p. 20). Em seguida, ela apresenta uma inferência bastante pessoal, novamente se colocando dentro do texto, como parte da história: "[...] with this glimpse into the noble Christian soul of Anne Gilchrist, it becomes interesting to see how the certain poems to which Rossetti referred were received by her" 24 (GOULD, 1900, p. 22). A biógrafa faz questão de manter a imagem de Anne como alguém que, apesar de situar-se à frente do seu tempo, é respeitável e composta. Ao referir-se às palavras usadas por Whitman nos seus poemas, que causaram espanto e até mesmo aversão no grande público da época, Gould (1900) explica:

"Who so well able to bear it", she asks, "as she who, having been a happy wife and mother, has learned to accept all things with tenderness, to feel a sacredness in all?" Her only doubt was expressed in the thought that perhaps Whitman had forgotten, or through some theory in his head had overridden, the truth that "our instincts are beautiful facts of nature as well as our bodies", and that we have a "strong instinct of silence about some things"25. (GOULD, 1900, p. 22).

Anne Gilchrist tinha consciência do próprio potencial intelectual. Ela estava muito à frente das mulheres da sua época, mulheres que, na sua grande maioria, somente tiveram oportunidade de adquirir uma educação básica, rasa e muito limitada. Alcaro (1991) diz que seria falsa modéstia por parte de Anne negar que poucas mulheres tinham o preparo ou a capacidade para ler os poemas de Whitman da forma que ela lia e captar a magnificência de sua obra:

In the "fleshy" poems, so offensive to others, she had found assurance that the inhibitions, taboos, and medical misinformation that had smothered her natural feelings and instincts were absurdities, and, with a heady new sense

\footnotetext{
${ }^{22}$ Do original: "Ela costumava achar que era bom 'desconsiderar a felicidade, persistir atrás de um objetivo despreocupadamente, a desprezando’. Agora ela viu que não há nada tão maravilhoso quanto ‘ser capaz da felicidade’; colhendo-a 'a cada momento e a qualquer coisa que aconteça'; descobrir que se pode' andar 'tão feliz e flutuante pelas bravas, ameaçadoras e tumultuosas ondas da vida, como aqueles que deslizam e reluzem sob o céu azul'; que não é 'derrota e desventura que provém da tempestade da Adversidade, mas força e calma’” (GOULD, 1900, p. 18, tradução nossa).

${ }^{23}$ Do original: “[...] como nunca antes, ela percebeu a glória de ser mulher, de ser mãe” (GOULD, 1900, p. 20, tradução nossa).

${ }^{24}$ Do original: “[...] com este vislumbre da nobre alma cristã de Anne Gilchrist, torna-se interessante ver como os poemas aos quais Rossetti se referia foram recebidos por ela” (GOULD, 1900, p. 22, tradução nossa).

${ }^{25}$ Do original: “' Quem pode melhor aguentar’, ela pergunta, ‘do que ela, que, tendo sido uma esposa e mãe feliz, aprendeu a aceitar todas as coisas com ternura, a sentir o sagrado em tudo?’ Sua única dúvida foi expressa no pensamento que, talvez Whitman tenha esquecido, ou através de alguma teoria na sua cabeça tenha anulado, a verdade que 'nossos instintos são lindos fatos da natureza assim como nossos corpos', e que temos um ‘forte instinto de silêncio sobre algumas coisas'” (GOULD, 1900, p. 22, tradução nossa).
} 
of freedom, she knew that she could response to the poet with her body as ecstatically as she had with her mind ${ }^{26}$. (ALCARO, 1991, p. 121-122).

\section{III}

Dosse (2009), como mencionado anteriormente, explica que a biografia traz uma "expectativa de verdade”, algo que se encontra entre a realidade e a ficção. Isso se deve ao fato de que é impossível reproduzir fielmente a vida de uma pessoa na sua totalidade. O biógrafo nunca terá acesso a todas as informações, a todos os sentimentos, a todos os fatos. Essas lacunas são, então, preenchidas pela imaginação do biógrafo, o que, na visão de Dosse, torna a biografia um gênero híbrido (DOSSE, 2009). A biografia de Gould é um claro exemplo deste hibridismo assinalado por Dosse (2009). A biógrafa Elisabeth Porter Gould, muitas vezes, aparece no texto biográfico, como quando ela cita suas conversas com Walt Whitman sobre um trabalho anterior: "[...] [h]e had already sent me two most appreciative letters for the article on his life among the soldiers included in the book, when it appeared in the New York Critic"27 (GOULD, 1900, p. 37). A biografia toda é permeada de citações sem menção às fontes, o que faz com que a confirmação de veracidade de alguns dos fatos seja bastante difícil. É importante destacarmos, no entanto, que a maior parte das informações sobre Anne, contidas no livro, foram conseguidas através da biografia escrita por Herbert Gilchrist, publicada em 1887. A biografia de Gould apesenta traços que a enquadram no que Pereira (2012) chama de "tradição processual” da concepção de uma biografia, na qual o biógrafo se faz visível e, em vez de atentar para a cronologia dos fatos, preocupa-se em mostrar a sua admiração ao biografado, muitas vezes expressando sua própria opinião.

\section{Referências}

ALCARO, M. W. Walt Whitman's Mrs. G.: A Biography of Anne Gilchrist. New Jersey: Associated University Press, 1991.

DOSSE, F. O desafio biográfico: escrever uma vida. Tradução Gilson César Cardoso de Souza. São Paulo: Editora da Universidade de São Paulo, 2009.

DUARTE, C. L. Arquivos de mulheres e mulheres anarquivadas: histórias de uma história mal contada. Estudos de Literatura Brasileira Contemporânea, Brasília, n. 30, p. 63-70, 2018.

GILCHRIST, H. Anne Gilchrist: her life and her writings. London: T. Fischer Unwin, 1887.

\footnotetext{
${ }^{26}$ Do original: “Nos poemas 'carnais', tão ofensivos aos outros, ela havia encontrado segurança que as inibições, tabus e as más informações médicas que haviam sufocado seus sentimentos naturais e seus instintos eram absurdos e, com um novo sentimento de liberdade, ela sabia que poderia responder ao poeta com seu corpo com tanto êxtase quanto havia com sua mente" (ALCARO, 1991, p. 121-122, tradução nossa).

${ }^{27}$ Do original: “[...] ele já me havia enviado duas cartas de agradecimento pelo artigo sobre sua vida entre os soldados incluído no livro, por ocasião da sua publicação no New York Critic” (GOULD, 1900, p. 37, tradução nossa).
} 
GOULD, E. P. Anne Gilchrist and Walt Whitman. Philadelphia: David McKay Publisher, 1900. HARNED, T. B. (ed.). The Letters of Anne Gilchrist. New York: Doubleday, 1918.

HOHLFELDT, A. Exercícios biográficos: arqueologia cultural. In: GUTFREIND, C. (org.). Narrar o biográfico: a comunicação e a diversidade da escrita. Porto Alegre: Sulina, 2015. p. 41-79.

LAGES, S. K. Walter Benjamin: tradução e melancolia. São Paulo: EDUSP, 2002.

MOMIGLIANO, A. The development of Greek biography. Cambridge: Cambridge University Press, 1993.

MONTAGNER, M. A. Trajetórias e biografias: notas para uma análise bourdieusiana. Sociologias, Porto Alegre, ano 9, n. 17, p. 240-264, jan./jun. 2007.

NÜNNING, A. On the perspective structure of narrative texts: steps towards a Constructivist Narratology. In: PEER, W. V.; CHATMAN, S. (ed.). New perspectives on narrative perspective. New York: State University of New York Press, 2001. p. 207-224.

PEREIRA, A. M. Biografia literária: duas tradições. Outra Travessia, Florianópolis, n. 14, p. 37-48, 2012.

SCHMIDT, B. B. Biografia: um gênero de fronteira entre a História e a Literatura. In: RAGO, M.; GIMENES, R. A. O. (org.). Narrar o passado, repensar a história. Campinas: UNICAMP, 2014. p. 191-202.

SCHMIDT, R. T. Descentramentos/convergências: ensaios de crítica feminista. Porto Alegre: Editora da UFRGS, 2017.

WATT, I. A ascensão do romance: estudos sobre Defoe, Richardson e Fielding. Tradução Hildegard Feist. São Paulo: Companhia das Letras, 1957.

WHITLEY, E. Walt_Whitman@pfaffs.bar: Bohemia on the World Wide Web. Mickle Street Review, 19/20, 2008. Disponível em: http://msr-archives.rutgers.edu/Scholarship/essays/ Whitley.pdf. Acesso em: 17 jan. 2022. 